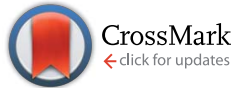

Cite this: Chem. Sci., 2014, 5, 3958

\title{
A Lewis acid/metal amide hybrid as an efficient catalyst for carbon-carbon bond formation $\dagger$
}

\begin{abstract}
Yasuhiro Yamashita, Yuki Saito, Takaki Imaizumi and Shū Kobayashi*
While Lewis acids and metal amides are among the most frequently used metal species, they are believed to be incompatible when combined. Here we describe a Lewis acid/metal amide hybrid, which contains electron-withdrawing groups and basic and bulky nitrogen functional groups in the same metal complex, as a novel catalyst. We have synthesized $\ln \left(\mathrm{N}\left(\mathrm{SiMe}_{3}\right)_{2}\right)_{2} \mathrm{Cl}\left(\ln (\mathrm{HMDS})_{2} \mathrm{Cl}\right)$ and $\ln (\mathrm{HMDS})_{2} \mathrm{OTf}$ as Lewis acid/metal amide hybrids, which showed excellent catalytic activity for the reaction of nitrones with terminal alkynes to give synthetically useful propargyl hydroxylamines. It is noted that neither the Lewis acids $\left(\operatorname{lnCl}_{3}, \ln (\mathrm{OTf})_{3}\right)$ nor the metal amides $\left(\operatorname{In}(\mathrm{HMDS})_{3}\right)$ have activity; only the hybrids worked well, and the catalytic activity of the hybrids was shown to be much higher than that of previously reported catalysts for this reaction. The concept of a Lewis acid/metal amide hybrid as a catalyst may be expanded to broad acid/base catalysis.
\end{abstract}

Received 7th May 2014

Accepted 6th June 2014

DOI: $10.1039 / \mathrm{c} 4 \mathrm{sc} 01332 \mathrm{~h}$

www.rsc.org/chemicalscience

basic and bulky nitrogen functional groups in the same metal complex (Fig. 1B). The hybrid is expected to work as a Lewis acid as well as a Brønsted base. ${ }^{9,10}$

Lewis acids have often been used in organic chemistry as promoters (stoichiometric use) and catalysts (catalytic use)., ${ }^{1,2}$ Friedel-Crafts acylation and alkylation with $\mathrm{AlCl}_{3}$ are typical examples; ${ }^{3}$ more recently, several stereoselective reactions catalyzed by Lewis acids have been developed. ${ }^{4,5}$ On the other hand, lithium diisopropylamide (LDA) and potassium hexamethyldisilazide (KHMDS) are typical examples of metal amides; ${ }^{6,7}$ these amides abstract acidic protons to generate nucleophilic species such as carbanions for carbon-carbon bond-forming reactions (Fig. 1A). Thus, while Lewis acids and metal amides are among the most frequently used metal species, these are acids and bases, and have been believed to be incompatible when combined. ${ }^{1,2,8}$

In Lewis acids, the metal parts play key roles, and stronger electron-withdrawing counter anions such as halides and trifluoromethanesulfonate (triflate), which lower the LUMO energy of the metal complexes and thus increase the Lewis acidity of the metals, have been investigated. On the other hand, nitrogen atoms play key roles in metal amides. Indeed, nitrogen atoms have two functions, nucleophilicity and basicity. ${ }^{8}$ To utilize only the base function, sterically bulky metal amides have been developed. ${ }^{6,7}$ Here, we report a Lewis acid/metal amide hybrid, which contains electron-withdrawing groups and

Department of Chemistry, School of Science, The University of Tokyo, Hongo, Bunkyo-ku Tokyo, Japan.E-mail: shu_kobayashi@chem.s.u-tokyo.ac.jp

$\dagger$ Electronic supplementary information (ESI) available: NMR study of the In catalyst structure, general experimental procedures, DFT calculations of the LUMO energy levels of the In complexes, and physical data of the products. CCDC 928541. For ESI and crystallographic data in CIF or other electronic

format see DOI: $10.1039 / \mathrm{c} 4 \mathrm{sc} 01332 \mathrm{~h}$

\section{Results and discussion}

Indium is in group 13, and In(III) is one of the most stable oxidation states. $\mathrm{InCl}_{3}$ and $\mathrm{In}(\mathrm{OTf})_{3}$ are known as typical In(III) Lewis acids. ${ }^{1}$ On the other hand, $\operatorname{In}\left(\mathrm{N}\left(\mathrm{SiMe}_{3}\right)_{2}\right)_{3}\left(\operatorname{In}(\mathrm{HMDS})_{3}\right)$ is known as a typical In amide. ${ }^{11-13}$ We prepared In(HMDS) ${ }_{2} \mathrm{Cl}$ as an In(III) Lewis acid/amide hybrid. ${ }^{14}$ The preparation was conducted by mixing 1 equiv. of $\mathrm{InCl}_{3}$ and 2 equiv. of KHMDS in THF at room temperature. After $12 \mathrm{~h}$, the mixture was filtered, and purification by sublimation and recrystallization gave pure In(HMDS $)_{2} \mathrm{Cl}$; its structure was confirmed by X-ray crystallographic analysis (Fig. 2). ${ }^{15}$

Next, to demonstrate the catalytic activity of this In(III) Lewis acid/amide hybrid, a model reaction of nitrones with terminal

(A)

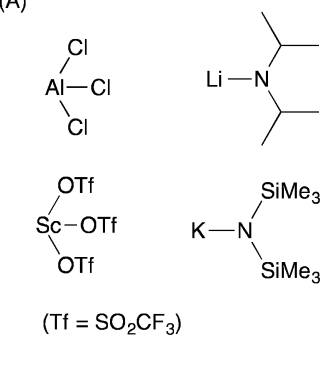

Typical LA
Fig. 1 (A) A typical Lewis acid (LA) and metal amide (MA); (B) a Lewis acid/metal amide hybrid (LA/MA hybrid).
(B)

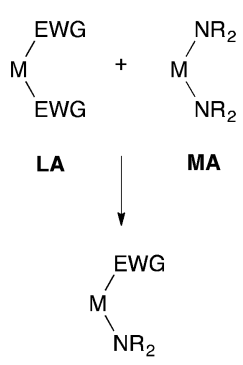

LA/MA Hybrid 


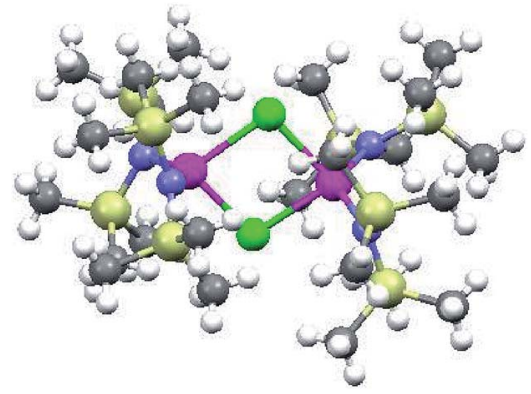

Fig. 2 The structure of $\ln \left(\mathrm{N}\left(\mathrm{SiMe}_{3}\right)_{2}\right)_{2} \mathrm{Cl}\left(\ln (\mathrm{HMDS})_{2} \mathrm{Cl}\right)$ from X-ray crystallographic analysis.

alkynes was examined. ${ }^{16-19}$ The catalytic addition of terminal alkynes to nitrones provides an efficient route to propargyl hydroxylamines, which can be further transformed into isoxazolines $^{20}$ and aziridines ${ }^{21}$ via intramolecular cyclization. In the literature, only a couple of catalyst systems have been reported for this reaction. Carreira $e t a l$. are pioneers and have shown that the combination of $\mathrm{Zn}(\mathrm{OTf})_{2}(10 \mathrm{~mol} \%)$ and ${ }^{\mathrm{i}} \mathrm{Pr}_{2} \mathrm{NEt}$ (25 $\mathrm{mol} \%$ ) is a suitable catalyst system. ${ }^{16}$ It was also reported that the combination of $\operatorname{InBr}_{3}(15 \mathrm{~mol} \%)$ and ${ }^{\mathrm{i}} \mathrm{Pr}_{2} \mathrm{NEt}(20 \mathrm{~mol} \%)$ is an alternative catalyst system. ${ }^{18}$ In both cases, however, the combination of a Lewis acid and a tertiary amine was needed. While the reaction also proceeded in the presence of a substoichiometric amount of $\mathrm{Et}_{2} \mathrm{Zn}(20 \mathrm{~mol} \%){ }^{18}$ in all these cases, relatively high loading amounts of Lewis acids (10-20 mol\%) and external tertiary amines (20-25 mol\%) were required to catalyze the reaction. ${ }^{22}$ We selected the reaction of nitrone 1a, derived from benzaldehyde and benzylhydroxyamine, with phenylacetylene $\mathbf{2 a}$ as a model, and several catalysts were examined (Table 1).

When $5 \mathrm{~mol} \%$ of $\operatorname{InCl}_{3}, \operatorname{In}(\mathrm{HMDS})_{3}$, or In(OTf $)_{3}$ was used at $40^{\circ} \mathrm{C}$ for $3 \mathrm{~h}$, the reaction did not proceed at all (entries 1-3). On the other hand, in the presence of $\operatorname{In}(\mathrm{HMDS})_{2} \mathrm{Cl}$, the reaction proceeded smoothly under identical reaction conditions to give the desired compound in $84 \%$ yield (entry 4 ). We further examined other indium salts. When In(HMDS) $\mathrm{Cl}_{2}$ was used, the product was obtained in $5 \%$ yield (entry 5); however, in the presence of In(HMDS $)_{2} \mathrm{OTf}^{23}$ and In(HMDS)(OTf $)_{2}$, the product yields were $88 \%$ and $86 \%$, respectively (entries 6,7 ). The use of 2,2,6,6-tetramethylpiperidide (TMP) in place of HMDS (In(TMP) $)_{2} \mathrm{OTf}$ ) gave a $12 \%$ yield of the product (entry 8 ), while the corresponding alkoxide $\left(\mathrm{In}\left(\mathrm{O}^{t} \mathrm{Bu}\right)_{2} \mathrm{OTf}\right)$ gave no product (entry 9$). \operatorname{In}\left(\mathrm{O}^{\mathrm{i}} \mathrm{Pr}\right)_{3}$ was also found to give no product (entry 10). We further examined the catalytic activity of these In(III) Lewis acid-In(III) amide hybrids at a loading of $1 \mathrm{~mol} \%$ at $25^{\circ} \mathrm{C}$ for $3 \mathrm{~h}$ (Table 1).

We found that In(HMDS $)_{2} \mathrm{OTf}$ showed the highest activity among the hybrids. The order of catalytic activity is as follows: In(HMDS $)_{2} \mathrm{OTf}>\operatorname{In}(\mathrm{HMDS})_{2} \mathrm{Cl} \gg \operatorname{In}(\mathrm{HMDS})(\mathrm{OTf})_{2}, \mathrm{In}(\mathrm{HMDS})$ $\mathrm{Cl}_{2}, \mathrm{In}(\mathrm{TMP})_{2} \mathrm{OTf}>\operatorname{In}\left(\mathrm{O}^{t} \mathrm{Bu}\right)_{2} \mathrm{OTf}$. It is noted that neither the Lewis acid $\left(\operatorname{InCl}_{3}, \operatorname{In}(\mathrm{OTf})_{3}\right)$ nor the metal amide (In(HMDS $\left.)_{3}\right)$

Table 1 Screening of Indium catalysts ${ }^{a}$

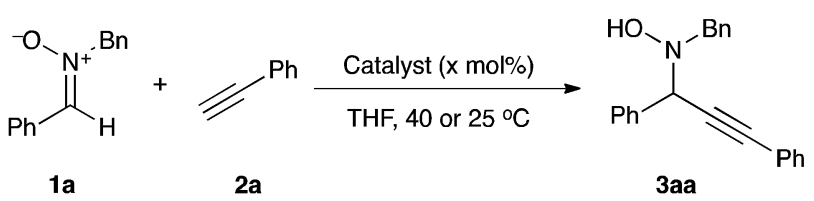

1.1 equiv

\begin{tabular}{|c|c|c|c|}
\hline \multirow[b]{2}{*}{ Entry } & \multirow[b]{2}{*}{ Catalyst } & \multicolumn{2}{|l|}{ Yield $^{b}(\%)$} \\
\hline & & $\begin{array}{l}5 \mathrm{~mol} \%, 40{ }^{\circ} \mathrm{C} \\
\text { (condition A) }\end{array}$ & $1 \mathrm{~mol} \% 25^{\circ} \mathrm{C}$ (condition $\left.\mathrm{B}\right)$ \\
\hline 1 & $\mathrm{InCl}_{3}$ & 0 & - \\
\hline 2 & $\operatorname{In}(\mathrm{HMDS})_{3}$ & 0 & - \\
\hline 3 & $\operatorname{In}(\mathrm{OTf})_{3}$ & 0 & - \\
\hline 6 & $\mathrm{In}(\mathrm{HMDS})_{2} \mathrm{OTf}^{e}$ & 88 & $38(92)^{i}, 35^{j}$ \\
\hline 7 & $\operatorname{In}(\mathrm{HMDS})(\mathrm{OTf})_{2}{ }^{f}$ & 86 & $<5$ \\
\hline 8 & $\mathrm{In}(\mathrm{TMP})_{2} \mathrm{OTf}^{g}$ & 12 & $<5$ \\
\hline 9 & $\mathrm{In}\left(\mathrm{O}^{t} \mathrm{Bu}\right)_{2} \mathrm{OTf}^{h}$ & 0 & - \\
\hline 10 & $\operatorname{In}\left(\mathrm{O}^{\mathrm{i}} \mathrm{Pr}\right)_{3}$ & 0 & - \\
\hline
\end{tabular}




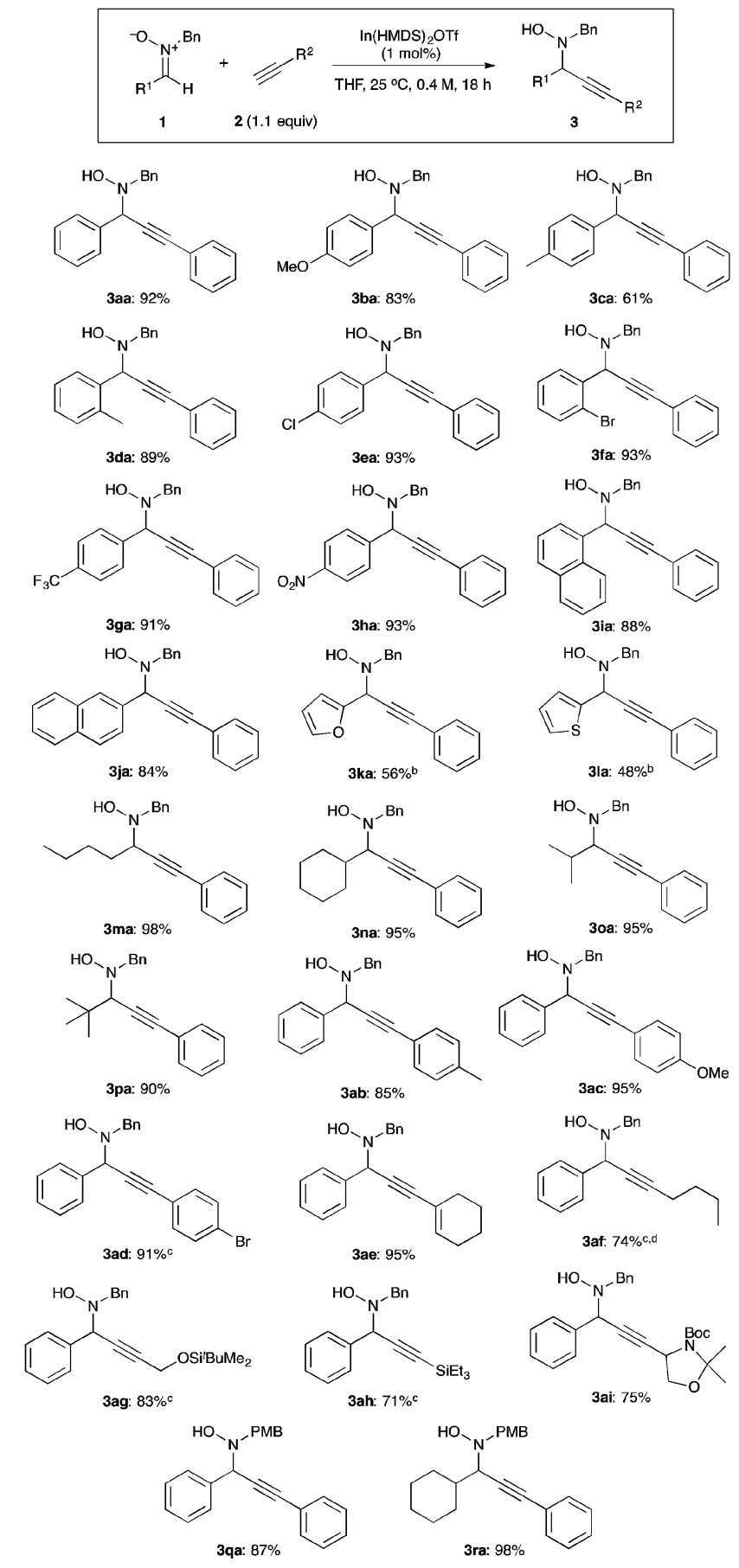

Fig. 3 Substrate scope of the reaction of nitrones with terminal alkynes using $\operatorname{In}(\mathrm{HMDS})_{2} \mathrm{OTf}$ as the catalyst. ${ }^{a}$ The reaction of 1 $(1.0 \mathrm{mmol})$ with $2(1.1 \mathrm{mmol})$ was performed in THF $(0.4 \mathrm{M})$ at $25^{\circ} \mathrm{C}$ using $\ln (\mathrm{HMDS})_{2} \mathrm{OTf}(1 \mathrm{~mol} \%)$ prepared from $\ln (\mathrm{HMDS})_{2} \mathrm{Cl}(0.012$ $\mathrm{mmol})$ and AgOTf $(0.010 \mathrm{mmol})$ unless otherwise noted. ${ }^{\mathrm{b}} 5 \mathrm{~mol} \%$ of the In catalyst was used. ${ }^{\mathrm{C}}$ The reaction was performed at $40^{\circ} \mathrm{C}$. ${ }^{\mathrm{d}}$ The reaction was performed for $36 \mathrm{~h}$.

showed any activity for the reaction, and that only the Lewis acid/metal amide hybrids gave the desired products. Moreover, the order of the catalytic activity among the hybrids is remarkable, and an exquisite balance between Lewis acidity and amide basicity is a key for high catalytic activity. ${ }^{24}$
Substrate scope of the reaction of nitrones with terminal alkynes using $\operatorname{In}(\mathrm{HMDS})_{2} \mathrm{OTf}$ as the catalyst was surveyed under the optimized reaction conditions (Fig. 3). In(HMDS) $)_{2} \mathrm{OTf}$ (1 mol\%) worked well with a wide variety of substrates to provide the desired propargyl hydroxylamines. The addition reaction of $\mathrm{N}$-benzylnitrones $\mathbf{1}$ derived from benzaldehyde derivatives bearing electron-donating substituents (1b-1d) with phenylacetylene $\mathbf{2 a}$ proceeded to give the desired adducts (3ba3da) in good yields. The nitrone bearing electron-withdrawing groups (1e-1h) were more reactive, and high yields were obtained under the same reaction conditions (3ea-3ha). The bulkier nitrones with 1- and 2-naphthyl groups (1i, $\mathbf{1 j})$ were also applicable to the addition reaction (3ia, 3ja), and nitrones prepared from heteroaromatic aldehydes $(\mathbf{1 k}, \mathbf{1 1})$ gave the desired products (3ka, 3la). The reactions using the nitrones prepared from several primary, secondary, and tertiary aliphatic aldehydes (1m-1p) proceeded smoothly to give the desired adducts in high yields (3ma-3pa). Several terminal alkynes 2 could also be used in this reaction. Phenylacetylene derivatives bearing electron-donating and electron-withdrawing substituents on the phenyl group (2b-2d) gave high yields (3ab-3ad). While a terminal alkyne bearing an alkenyl substituent (2e) was successfully employed in the desired reaction (3ae), alkynes bearing alkyl groups (2f, 2g) and a triethylsilyl group (2h) were less reactive, but high yields were obtained at higher temperature (3af-3ah). The terminal alkyne-bearing oxazolidine moiety (2i) reacted without losing any protecting group (3ai). The $p$-methoxybenzyl group could also be employed as a protecting group on the nitrogen atom (3qa, 3ra). ${ }^{25}$

The efficiency of the Lewis acid/metal amide hybrid catalyst was also demonstrated in a gram-scale experiment using 0.1 mol\% of the catalyst. In the presence of $0.1 \mathrm{~mol} \%$ of In(HMDS) $)_{2} \mathrm{OTf}, 1 \mathrm{a}$ reacted with $2 \mathrm{a}$ in $\mathrm{THF}$ at $25^{\circ} \mathrm{C}$ for $36 \mathrm{~h}$ to give the desired propargyl hydroxylamine 3 aa in $90 \%$ yield (Fig. 4 ).

A proposed catalytic cycle of this reaction is shown in Scheme 1. Initially, terminal alkyne 2 is activated by $\operatorname{In}(\mathrm{HMDS})_{2} \mathrm{X}(\mathrm{X}=\mathrm{Cl}$ or OTf) to form indium acetylide I. This step was independently confirmed by NMR analysis. It is noted that the Brønsted basicity of In(HMDS $)_{2} \mathrm{X}$ enables this process and that this step does not proceed at all using a conventional Lewis acid such as $\mathrm{InCl}_{3}$ and In(OTf $)_{3}$. Acetylide $\mathbf{I}$ then reacts with nitrone $\mathbf{1}$ to give adduct III via addition step II, in which the Lewis acidity of the indium bearing electron-withdrawing group $\mathrm{X}$ is important to activate nitrone 1. Thus, both the Lewis acidity and Brønsted basicity of In(HMDS $)_{2} \mathrm{X}$ are crucial for this reaction, and moreover, an exquisite balance between the Lewis acidity and Brønsted basicity of the Lewis acid-metal amide hybrids is also key for this reaction. Finally, adduct III reacts with $\mathrm{HN}(\mathrm{HMDS})_{2}$ to give product 3 along with the regeneration of $\operatorname{In}(\mathrm{HMDS})_{2} \mathrm{X}^{26}$

In addition to being a conceptual advance and having a high catalytic activity, this Lewis acid/metal amide hybrid has another synthetic advantage as a catalyst in tandem-type reactions with other catalysts. In the presence of $5 \mathrm{~mol} \%$ of In(HMDS $)_{2} \mathrm{Cl}$ and $20 \mathrm{~mol} \%$ of AgOTf, 1a reacted with 2a to give a 4-isoxazoline derivative (4aa) directly in high yield (Fig. 5A). ${ }^{20}$ Moreover, in the presence of $5 \mathrm{~mol} \%$ of $\operatorname{In}(\mathrm{HMDS})_{2} \mathrm{Cl}$ and $20 \mathrm{~mol} \%$ of CuOTf, 1a reacted with $2 \mathrm{a}$ to give an aziridine 


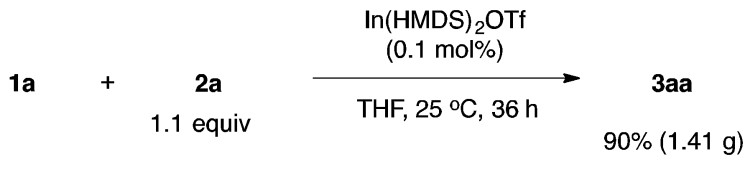

Fig. 4 A gram-scale synthesis using 0.1 mol\% of the catalyst.

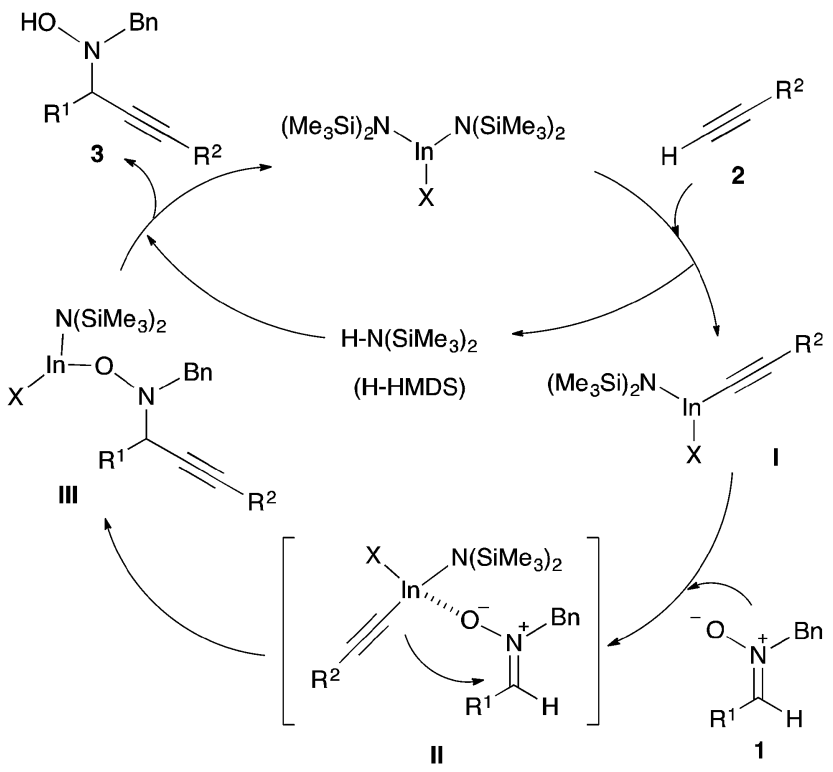

Scheme 1 A proposed catalytic cycle (X $=\mathrm{Cl}$ or OTf).

(A)

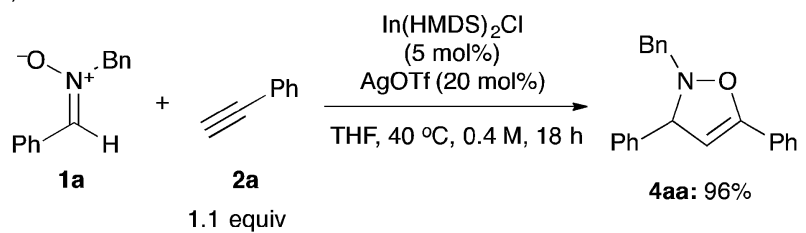

(B)

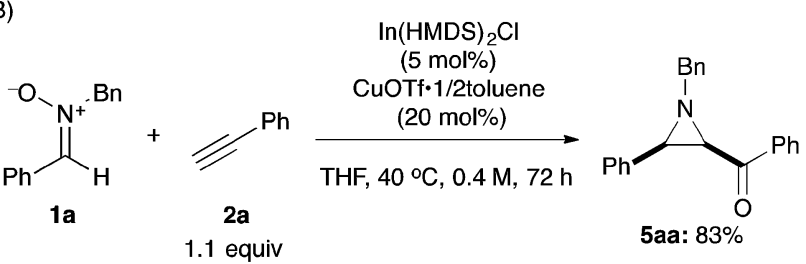

Fig. 5 Tandem addition/cyclization reactions leading to isoxazoline (A) and aziridine (B).

product (5aa) in high yield (Fig. 5B). ${ }^{21}$ In these cases, In(HMDS) ${ }_{2} \mathrm{X}$ (the Lewis acid/metal amide hybrid) is compatible with Lewis acids such as AgOTf and CuOTf, and the tandem addition/cyclization reactions proceeded smoothly in one pot. ${ }^{27}$

The concept of a Lewis acid/metal amide hybrid as a catalyst could be expanded to other acid/base catalyses. In preliminary results, In(HMDS $)_{2} \mathrm{Cl}$ was found to be effective for the reaction of 2a with aldehyde 7a (Fig. 6A). Moreover, In(HMDS) $)_{2} \mathrm{~F}$ was found to be an effective Lewis acid/metal amide hybrid catalyst for the reactions of $2 \mathbf{a}$ with $7 \mathbf{b}$ (Fig. 6B) and 2a with 7c (Fig. 6C).
(A)

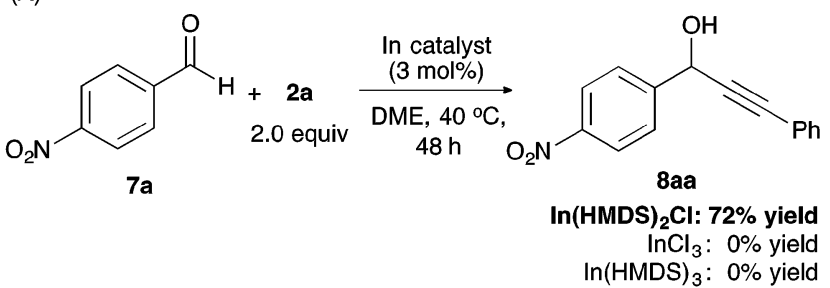

(B)<smiles>O=CC1CCCCC1</smiles>

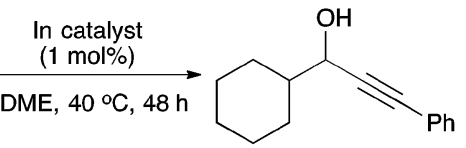

8 ba

In(HMDS) ${ }_{2} \mathrm{~F}: 76 \%$ yield $\operatorname{InF}_{3}: 0 \%$ yield $\ln (\mathrm{HMDS})_{3}: 0 \%$ yield

(C)
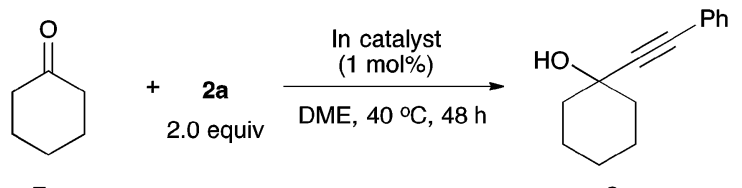

In(HMDS)
I F: quant $\mathrm{InF}_{3}: 0 \%$ yield $\ln (\mathrm{HMDS})_{3}: 0 \%$ yield

Fig. 6 Other Lewis acid-metal amide hybrids and catalyses.

\section{Conclusions}

We have synthesized In(HMDS $)_{2} \mathrm{Cl}$ and In(HMDS $)_{2} \mathrm{OTf}$ as In(III) Lewis acid/amide hybrids. These hybrids showed excellent catalytic activities for the reaction of nitrones with terminal alkynes to give synthetically useful propargyl hydroxylamines in good to high yields. It is noted that neither Lewis acids $\left(\mathrm{InCl}_{3}, \operatorname{In}(\mathrm{OTf})_{3}\right)$ nor metal amides (In(HMDS $)_{3}$ ) have catalytic activity but only hybrids work well for this reaction. The catalyst loading is low (0.1-1 mol\%) compared with those of the previous Lewis acid-tertiary amine systems (10-25 mol\%), and the hybrid is compatible with other Lewis acids to realize tandem reactions in one pot. The concept of a Lewis acid/metal amide hybrid as a catalyst described in this paper may be expanded to broader acid/base catalysis and preliminary results were shown. Further investigations on this concept are currently underway in our laboratory.

\section{Acknowledgements}

This work was partially supported by a Grant-in-Aid for Scientific Research from the Japan Society for the Promotion of Science (JSPS) and Japan Science and Technology Agency (JST). T. I. thanks the JSPS Research Fellowship for Young Scientists.

\section{Notes and references}

1 Lewis Acids in Organic Synthesis, ed. H. Yamamoto, WileyVCH, Weinheim, 2000.

2 Acid Catalysis in Modern Organic Sysnthesis, ed. H. Yamamoto and K. Ishihara, Wiley, New York, 2008. 
3 Friedel-Crafts and Related Reactions, ed. G. A. Olah, Wiley, New York, 1963, Vol. 1-4.

4 Catalytic Asymmetric Synthesis, ed. I. Ojima, Wiley, New York, 3rd edn, 2010, see also ref. 1 and 2.

5 S. Kobayashi, Y. Mori, J. S. Fossy and M. M. Salter, Chem. Rev., 2011, 111, 2626-2704.

6 J. Emaes, Sci. Synth., 2006, Vol. 8a, 173-241.

7 P. Venturello and M. Barbero, Sci. Synth., 2006, Vol. 8b, 13991436.

8 Metal Amide Chemistry, ed. M. Lappert, P. Poer, A. Protchenko and A. Seeber, Wiley-VCH, Weinheim, 2009.

9 For the concept of metal amides as simple acid/base catalysts, see: (a) Y. Yamashita and S. Kobayashi, Chem. Eur. J., 2013, 19, 9420-9427; (b) Y. Yamashita, X.-X. Guo, R. Takashita and S. Kobayashi, J. Am. Chem. Soc., 2010, 132, 3262-3263; (c) Y. Yamashita, T. Imaizumi and S. Kobayashi, Angew. Chem., Int. Ed., 2011, 50, 4893-4896; (d) Y. Yamashita, T. Imaizumi, X.-X. Guo and S. Kobayashi, Chem. - Asian J., 2011, 6, 2550-2559; (e) T. Imaizumi, Y. Yamashita and S. Kobayashi, J. Am. Chem. Soc., 2012, 134, 20049-20052.

10 Chlorotantalum amide and anilide complexes $\left(\left[\mathrm{TaCl}_{3}\left(\mathrm{NEt}_{2}\right)_{2}\right]\right)_{2}$ and $\left(\left[\left(\mathrm{TaCl}_{3}(\mathrm{NMePh})_{2}\right)\right]_{2}\right)$ were reported to catalyze the hydroalkylation of olefins. S. B. Herzon and J. F. Hartwig, J. Am. Chem. Soc., 2008, 130, 14940-14941.

11 H. Buerger, J. Cichon, U. Goetze, U. Wannagat and H. J. Wismar, J. Organomet. Chem., 1971, 33, 1-12.

12 A. J. Edwards, A. Fallaize, P. R. Raithby, M.-A. Rennie, A. Steiner, K. L. Verhorevoort and D. S. Wright, J. Chem. Soc., Dalton Trans., 1996, 133-137.

13 M. Yamaguchi, N. Morita, U. Schneider and S. Kobayashi, Adv. Synth. Catal., 2010, 352, 1461-1465.

14 E. A. Mazurenko, L. I. Tsymbal and L. I. Zheleznoval, Ukr. Khim. Zh., 2000, 66, 13-17. In this report, In(HMDS) $)_{2}$ Cl was described; however, its characterization was not enough and the synthetic method was unclear.

15 Data have been deposited with the Cambridge Crystallographic Data Centre under the organic and organometallic compounds as entry CCDC 928541.
16 (a) D. E. Frantz, R. Fässler and E. M. Carreira, J. Am. Chem. Soc., 1999, 121, 11245-11246; (b) D. E. Frantz, R. Fässler, C. S. Tomooka and E. M. Carreira, Acc. Chem. Res., 2000, 33, 373-381.

17 S. Pinet, S. U. Pandya, P. Y. Chauant, A. Ayling and Y. Valee, Org. Lett., 2002, 4, 1463-1466.

18 D.-M. Ji and M.-H. Xu, Tetrahedron Lett., 2009, 50, 2952.

19 Stoichiometric reactions: (a) W. Wei, M. Kobayashi, Y. Ukaji and K. Inomata, Chem. Lett., 2006, 35, 176-177; (b) A. Konishi, W. Wei, M. Kobayashi, S. Fujinami, Y. Ukaji and K. Inomata, Chem. Lett., 2007, 36, 44-45; (c) T. Bunlaksananusorn, T. Lecourt and L. Micouin, Tetrahedron Lett., 2007, 48, 1457-1459.

20 N. Wada, K. Kaneko, Y. Ukaji and K. Inomata, Chem. Lett., 2011, 40, 440-442.

21 Y. Miyamoto, N. Wada, T. Soeta, S. Fujinami, K. Inomata and Y. Ukaji, Chem. - Asian J., 2013, 8, 824-831.

22 Presumably due to the high basicity of nitrones and products, most catalysts might be trapped and the turnover of the catalysts might be difficult or low to moderate. This is contrary to the related reactions of imines with terminal alkynes, where many catalysts have been reported. For example, see: T. Ohshima, To Catalytic Asymmetric 1,2-Alkynylation in Comprehensive Chirality, ed. M. Shibasaki, E. M. Carreira and H. Yamamoto, Elsevier, Amsterdam, 2012, pp. 355-377.

23 Although $\mathrm{AgCl}$ formed in the catalyst preparation, it was confirmed that $\mathrm{AgCl}$ played no role in the reaction system. See the results in Table 6, entry 6, condition B.

24 DFT calculations of the LUMO energy levels of the In complexes were performed. See the ESI $\dagger$

25 S. D. Bull, S. G. Davies, G. Fenton, A. W. Mulvaney, R. S. Prasad and A. D. Smith, J. Chem. Soc., Perkin Trans. 1, 2000, 3765-3774.

26 A referee suggested the possibility that the dimer of the Lewis acid-metal amide hybrid worked as a homobimetallic catalyst. We cannot rule out this possibility. 27 The tandem reactions were not successful using $\mathrm{Zn}(\mathrm{OTf})_{2}-{ }^{\mathrm{i}} \mathrm{Pr}_{2} \mathrm{NEt}^{16}$ and $\mathrm{InBr}_{3}-{ }^{\mathrm{i}} \mathrm{Pr}_{2} \mathrm{NEt}^{18}$ systems. Details are shown in the ESI. $\dagger$ 